\title{
Editorial: Active Fold-and-Thrust Belts: From Present-Day Deformation to Structural Architecture and Modelling
}

\author{
Gang Rao ${ }^{1,2 *}$, Maryline Le Béon ${ }^{3}$, Renqi $L^{4}{ }^{4}$, Fabien Graveleau ${ }^{5}$, Jonny $W u^{6}$ and \\ Bernard Delcaillau ${ }^{7}$
}

${ }^{1}$ School of Geoscience and Technology, Southwest Petroleum University, Chengdu, China, ${ }^{2}$ School of Earth Sciences, Zhejiang University, Hangzhou, China, ${ }^{3}$ Graduate Institute of Applied Geology, National Central University, Taoyuan, Taiwan, ${ }^{4}$ State Key Laboratory of Earthquake Dynamics, China Earthquake Administration, Institute of Geology, Beijing, China, ${ }^{5}$ Univ. Lille, CNRS, Univ. Littoral Côte d'Opale, UMR 8187-LOG-Laboratoire d'Océanologie et de Géosciences, Lille, France, ${ }^{6}$ Department of Earth and Atmospheric Science, University of Houston, Houston, TX, United States, ${ }^{7}$ UniCaen, UniRouen, CNRS, M2C, Université de Caen Normandie, Caen, France

Keywords: fold-and-thrust belts, active deformation, earthquake hazards, structural geology, analog and numerical modeling

Editorial on the Research Topic

Active Fold-and-Thrust Belts: From Present-Day Deformation to Structural Architecture and Modelling

OPEN ACCESS

Edited and reviewed by:

Derek Keir,

University of Southampton, United Kingdom

*Correspondence: Gang Rao

raogangss@126.com

Specialty section:

This article was submitted to Structural Geology and Tectonics, a section of the journal

Frontiers in Earth Science

Received: 16 November 2021 Accepted: 25 November 2021 Published: 14 December 2021

Citation: Rao G, Le Béon M, Lu R, Graveleau F, Wu J and Delcaillau B (2021) Editorial: Active Fold-and-Thrust Belts: From Present-Day Deformation to Structural Architecture and Modelling. Front. Earth Sci. 9:816157. doi: 10.3389/feart.2021.816157
Fold-and-thrust belts are a characteristic structural unit observed at the outer part of mountain belts and accretionary prisms formed along convergent plate boundaries. The active folds and thrusts usually develop at the piedmonts and within the foreland basins of active mountain belts. Here, human populations, fertile lands, infrastructures and economic centers are also commonly concentrated and hence exposed to seismic hazards. Coastal areas are exposed to tsunami hazards from active offshore fold-thrust structures. In addition, foreland basins and fold-andthrust belts host significant fossil energy resources. Hazard mitigation requires us to better understand the three-dimensional structure of fold-and-thrust belts, their seismic behavior and evolution. Earthquakes that occurred in the last couple of decades, newly-available ground-surface deformation observations from Sentinel satellites, the development of higher-resolution topographic models and the increased amount and quality of subsurface data acquired for oil and gas exploration purposes provide new opportunities to reach this goal. Enhanced exchanges between scientists from these different communities, also including modelers, are needed to address the issues mentioned above. The 23 papers in this research topic provide new insights into the structural development and evolution in the fold-and-thrust belts at multiple spatial and temporal scales.

Besides the occurrence of large earthquakes that are often associated with multi-fault or -segment ruptures, moderate earthquakes also show complex seismogenic behaviors. Based on the relocation and seismological analyses of the 2003 Ms 6.1 Minle earthquake sequence in Hexi Corridor Basin, Zou et al. found that this event is associated with a low-angle thrust fault beneath the Yonggu Anticline. Instead of producing surface ruptures, it is characterized by thrust-related folding, which is consistent with active deformation features revealed by the topographic surveys and OSL dating of river terraces. Yao et al. relocated the earthquake sequence of the 2020 M 6.4 Jiashi earthquake that occurred in the active Kepin fold-and-thrust belt, SW Tian Shan. After integrating with subsurface geometries revealed by seismic reflection profiles, they demonstrated that this event happened because of reactivated deep (below regional detachment), ancient structures within the basement. 
Based on observed borehole strain data and numerical simulations, Li Y. et al. provided further constraints on the seismogenic faulting of the $2016 \mathrm{Mw} 6.0$ Hutubi earthquake that occurred in the southern Junggar fold-and-thrust belt, northern Tian Shan. Instead of the major north-vergent Southern Junggar Thrust (the Huoerguosi-Manas-Tugulu fault branches at ground surface), the faulting occurred along a highangle back thrust. According to the characteristic features of offset landforms revealed by high-resolution UAV-acquired topographic data and field surveys, Huang $X$. et al. reevaluated the distribution and length of the surface ruptures produced by the AD 1609 M 7 1/4 Hongyapu earthquake along the Fodongmiao-Hongyazi thrust belt at the northern margin of the Qilian Shan. It is suggested that surface-rupturing of multiple segments with a total length of $>90 \mathrm{~km}$ yielded an earthquake magnitude of $M w 7.2-7.4$.

High-resolution topographic and imagery data together with the improved dating methods allowed geoscientists to provide more precise constraints on slip behaviors from observed tectonic landforms. In combination with unmanned aerial vehicle topographic surveys and trench investigations, Lei et al. demonstrated an eastward increase of slip rate from $\sim 0.7$ to $\sim 2.8 \mathrm{~mm} / \mathrm{yr}$ along the Fengle thrust fault, bounding the Yongchangnan Shan, northeastern Tibetan Plateau. They interpreted that the deformation in this region not only propagates northward but also eastward. Luo H. et al. determined the vertical and horizontal slip rates of the southern marginal fault of the Qaidam Basin to be $\sim 0.96$ and $\sim 2.66 \mathrm{~mm} / \mathrm{yr}$, respectively. Besides the major Kunlun left-lateral slip fault, they suggested that the other faults nearby have also accommodated strain in response to lateral extrusion of the Tibetan Plateau. Considering the effect of erosion and deposition processes acting on fault scarp morphologies, Liu et al. re-evaluated the vertical rate of the western Minle-Damaying thrust fault at the northern margin of the Qilian Shan. Furthermore, they confirmed that fault activity is weaker here compared to the middle and eastern segments of this fault. Based on detailed analysis of remotesensing imagery, field surveys and geological mapping, Yang et al. demonstrated the kinematics and late Quaternary deformation rate of the Huoyanshan structure, an important active fold-and-thrust belt in the eastern Chinese Tian Shan. A kinematic model of curved thrust fault propagation and folding was proposed, yielding a shortening rate of $2.0-3.2 \mathrm{~mm} / \mathrm{yr}$. The results highlight the importance of strain partitioning in the studied area. Hu et al. inferred a listric fault-fold model from surveying river terrace surfaces across an active fold, northern Qilian Shan, and compared it with fault geometries revealed by a seismic reflection profile. The results confirmed the reliability of the subsurface fault geometry estimated by deformed fluvial terraces.

Benefiting from the acquisition of seismic reflection profiles and other subsurface datasets, the geometry and kinematic evolution of folds and thrusts have been explored in detail. Huang $\mathrm{H}$. et al. demonstrated that multiple detachments have played significant roles in controlling the spatial and temporal patterns of deformation in the southwestern Dabashan, South China. Huang K. et al. identified two sets of orthogonal, basement-involved faults at the northwestern margin of the Qaidam basin with contrasting geometries, kinematics, and temporal development, suggesting a transition from transpression to left-lateral slip on the central segment of the Altyn Tagh fault system nearby. Wu H. et al. integrated stratigraphic, sedimentological, and borehole data with seismic profiles to demonstrate the Jurassic to Cretaceous extensional deformation subsequent to the Triassic contraction. $\mathrm{Ma}$ et al. integrated seismic profiles and outcrop data to unravel that deformation history of the Huoerguosi-Manas-Tugulu fold belt could date back to the Late Jurassic, prior to the late Cenozoic episode. The structural characteristics have also been reproduced by sandbox modeling experiments. Costantino et al. carried out palinspastic restorations of two cross-sections constructed with surface data and seismic information to explore the tectono-stratigraphic history of the eastern Cordillera of Colombia. The methodologies may also be applied in structural analyses of other fold-and-thrust belts with high erosion rates where growth strata are mostly eroded.

Both numerical and analog experiments are powerful in exploring structural evolution histories, and are often thought-provoking. Granado et al. presented a series of two-dimensional (2D) thermo-mechanical numerical experiments of stretching and contraction of extensional basins with pre-rift salt. They also compared their results to natural cases, providing important insights into the structural evolution of salt-related inversion tectonics. Inspired by the observations of structural deformation involving multiple detachments within the western Sichuan fold-and-thrust belts, central China, Sun et al. carried out a series of sandbox experiments to test the controls on lateral structural variations. The results demonstrated that varied mid-level detachments can alter depth-dependent deformation partitioning in such systems. Using analog experiments, Luo Q. et al. investigated the influence of variable erosion and sedimentation on the structural development of a fold-and-thrust belt. The distinctly different styles have been applied to explain the reason why the Cenozoic rejuvenated foreland basin was restricted to the southwestern corner of the Sichuan Basin. Wu Z. et al. carried out four groups of discrete element models to also explore the effects of regional erosion and sedimentary loading on the sequences of thrusting in central and southern Longmen Shan belt. Similar conclusions have been achieved, suggesting the comparability between these two methods. Following this theme, Li C. et al. provided a direct comparison between a commonly applied discrete element method and analog model in terms of fault geometry and thrust-wedge topography. It is suggested that calibration of the discrete element method is necessary and important, increasing confidence in these models for exploring deformation within fold-andthrust belts.

The Earth's surface is shaped jointly by tectonics and changes in climatic condition. Hence, tectonic information can often be 
extracted from landscape characteristics via geomorphological methods. Sun and Mann carried out a systematic analysis of morphotectonic indices of the drainage network in southeastern Papua New Guinea, extracted from digital topographic datasets. It is suggested that more localized geomorphological anomalies are related to structural transition due to the regional microplate rotation. Based on the collected thermochronological ages, Cai et al. inverted the denudation and relief history of the Lhasa River drainage in the late Cenozoic using a three-dimensional (3D) thermo-kinematic model. The results indicate a complex denudation history, and also emphasize that the impacts of enhanced Asian monsoon precipitation on fluvial erosion and hence topographic evolution in the central Gangdese region. On the basis of the corrected ${ }^{26} \mathrm{Al} /{ }^{10} \mathrm{Be}$ burial ages of sediments on the fans of the eastern piedmont of the Lu Mountain, Han et al. constrained the denudation rates to $0.033 \sim 0.082 \mathrm{~m} / \mathrm{kyr}$. In this regard, the hanging wall could have been eroded to its present position within 13-33 Myr. They proposed that the $\mathrm{Lu}$ Mountain was mainly uplifted in the Miocene due to crustal compressional deformation with the presence of the Xingzi reverse fault as its eastern boundary fault. Perez et al. integrated new results, including magnetostratigraphy and flexural modeling, with existing structural and thermochronological datasets to demonstrate the patterns of Cenozoic shortening, exhumation, and subsidence in the southern Bolivian Andes over time and space. The results emphasized the interplay between crustal and surface processes related to tectonics and Miocene climatic shifts.

In summary, the 23 high-quality original research articles gathered in this research topic represent a step forward in understanding the complex evolution of fold-and-thrust belts. More importantly, it is our hope that these studies offer new directions for future research that will guide future scientific community efforts.

\section{AUTHOR CONTRIBUTIONS}

All authors listed have made a substantial, direct and intellectual contribution to the work, and approved it for publication.

\section{ACKNOWLEDGMENTS}

Many thanks to all the authors for their contributions to this research topic, and patience during the review process. We are also grateful to the reviewers for their insightful comments and constructive suggestions, which greatly improved the clarity of the articles. We also thank DK and Yosuke Aoki for participating in editorial handling. Support throughout the process of assembling and publication from the Frontiers editorial team is highly appreciated. This work was supported by the Second Tibetan Plateau Scientific Expedition and Research (No. 2019QZKK0708) and the National Natural Science Foundation of China (No. 41872206).

Conflict of Interest: The authors declare that the research was conducted in the absence of any commercial or financial relationships that could be construed as a potential conflict of interest.

Publisher's Note: All claims expressed in this article are solely those of the authors and do not necessarily represent those of their affiliated organizations, or those of the publisher, the editors and the reviewers. Any product that may be evaluated in this article, or claim that may be made by its manufacturer, is not guaranteed or endorsed by the publisher.

Copyright (c) 2021 Rao, Le Béon, Lu, Graveleau, Wu and Delcaillau. This is an openaccess article distributed under the terms of the Creative Commons Attribution License (CC BY). The use, distribution or reproduction in other forums is permitted, provided the original author(s) and the copyright owner(s) are credited and that the original publication in this journal is cited, in accordance with accepted academic practice. No use, distribution or reproduction is permitted which does not comply with these terms. 